\title{
Peripheral nerve abnormalities related to galactose administration in rats
}

\author{
A. K. SHARMA, P. K. THOMAS, AND R. W. R. BAKER \\ From the Department of Neurology, Royal Free Hospital, and Department of Chemical Pathology, \\ Guy's Hospital Medical School, London
}

SYNOPSIS Electrophysiological, biochemical, and morphometric observations were made on the peripheral nerves of rats after galactose feeding. Motor nerve conduction velocity was found to be reduced. This was associated with an accumulation of galactitol in the peripheral nerves and a diminution in their myoinositol content. An increased water content and fascicular area, taken in conjunction with a probable increase in the area of the endoneurial spaces, indicated overhydration of the peripheral nerves. Morphometric observations on the myelinated fibre population in the tibial nerve showed no loss of fibres and, although both the maximal and the average diameter of the myelinated fibres was slightly less than in age-matched controls, this was insufficient to explain the reduction in conduction velocity. Segmental demyelination was not detected and the relationship between myelin thickness and axon circumference was not altered. Electron microscope observations revealed no ultrastructural changes in the myelinated fibres and, in particular, no abnormalities at the nodes of Ranvier or indi- $\mathrm{D}$ cation of abnormal hydration of the Schwann cells. The relevance of these findings to the peripheral nerve changes in human and experimental diabetes is discussed.

In hereditary galactosaemia in man cataracts become evident with increasing age in untreated children. This is associated with accumulation of the sugar alcohol galactitol in the lens (Gitzelmann et al., 1967) and the consequent osmotic damage is perhaps responsible for the development of the cataracts, which are similar to those that may develop in diabetics. Morphologically comparable cataracts also appear in rats after galactose feeding and after the induction of diabetes (Van Heyningen, 1959). Sugar cataracts in rats after galactose feeding and in diabetic animals are associated respectively with the accumulation of galactitol and sorbitol in sufficient quantities to produce osmotic effects in the lens (Van Heyningen, 1959; Kinoshita et al., 1962; Kinoshita, 1965; Gabbay, 1973). The role of sugar alcohols in the formation of cataracts in these situations has been discussed by Kinoshita (1965) and Gabbay (1973).

(Accepted 23 March 1976.)
In addition to the lens the peripheral nerves? also accumulate galactitol in galactose-fed rats, and this is accompanied by reduced motor nerve conduction velocity (Gabbay and Snider, 1972). These authors also reported that the peripheral nerves had an increased water content and became macroscopically swollen. Although the role of sugar alcohols in the origin of pathological changes in the lens seems clear, the significance of the accumulation of galactitol in relation to the disturbance of nerve conduction is uncertain. Morphological studies on this interesting model have not yet been presented. The present study reports electrophysiological, biochemical, and morphometric observations on the peripheral nerves after galactose administration in rats.

\section{METHODS}

The observations were made on male Wistar rats weighing between 300 and $400 \mathrm{~g}$. Age-matched animals were divided into experimental and control groups. The experimental animals were fed a diet containing four parts of D-galactose and six parts of 
41B Oxoid diet (Lillico). Control animals were fed 41B Oxoid chow pellets. The rats were maintained in plastic metabolic cages with water and food ad libitum.

ELECTROPHYSIOLOGICAL METHODS Serial measurements of motor nerve conduction velocity were made on control and galactose-fed rats by a method described by Sharma and Thomas (1974). The animal was anaesthetized with ether and placed on an electrically heated pad in a warm room. The intramuscular temperature in the hind limbs recorded with a needle thermometer ranged between 33 and $35^{\circ} \mathrm{C}$ and did not differ between the control and experimental groups. The right hind limb was held in full extension by strapping. A sterile concentric needle electrode (Disa type K0511) was inserted into the muscles of the first interosseous space in the foot. The position of the stimulating and recording electrodes is shown diagrammatically in Fig. 1. The sciatic nerve was stimulated through needle electrodes at the sciatic notch and the tibial nerve posterior to the medial malleolus by just supramaximal electrical stimuli delivered from a Devices isolated stimulator at a rate of one per second. The muscle action potentials were suitably amplified and displayed on an oscilloscope. Conduction time between the upper and lower stimulation sites was measured from photographs.

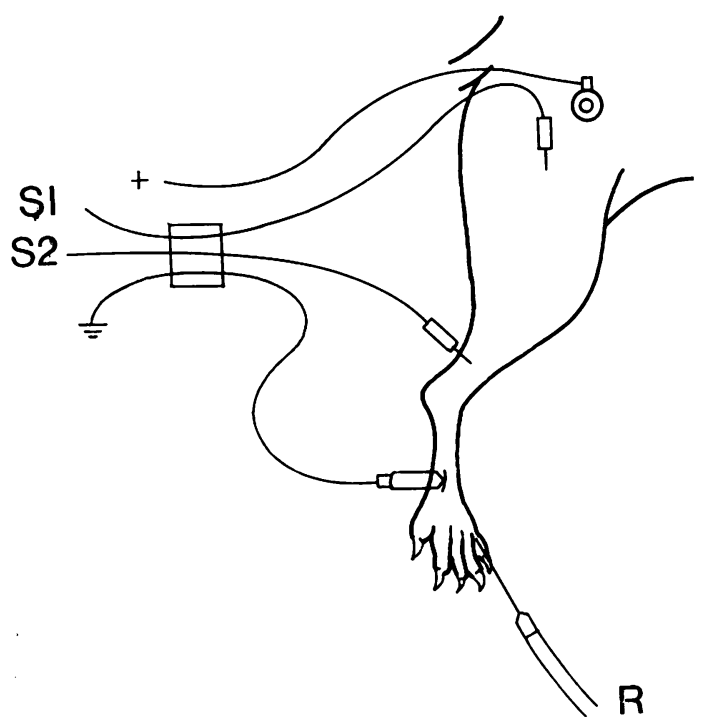

FIG. 1 Position of stimulating ( $S 1$ and S2) and recording $(R)$ electrodes employed for measurement of motor nerve conduction velocity.
The distance between the two stimulating points as estimated on the skin with calipers was taken as the conduction distance and divided by the conduction time to obtain velocity.

BIOCHEMICAL METHODS For biochemical determinations the animal was anaesthetized with ether and the right sciatic nerve freed from surrounding connective tissues from the sciatic notch to the lower thigh and removed in one piece. The water content was estimated by comparing the difference between the wet and dry weights of the nerve. For this purpose the nerves were weighed immediately after removal and dried for four hours at $80^{\circ} \mathrm{C}$. They were then reweighed after cooling in a dessicator over phosphorus pentoxide.

For the estimation of sugars and polyhydric alcohols, nerves which had been dried as above were each put into a tube silylized with Repelcote (BDH) and containing $1 \mathrm{ml}$ water together with $10 \mu l$ of internal standard (aqueous arabitol, $328 \mathrm{mmol} / \mathrm{l}$ ). The tube was placed in boiling water for 10 minutes and the liquid then decanted into a silylized centrifuge tube. The nerve was washed with a further $1 \mathrm{ml}$ of water, which was added to the first extract, and protein was coagulated by adding $0.30 \mathrm{ml} 40 \% \mathrm{w} / \mathrm{v}$ trichloracetic acid and heating in boiling water for two to three minutes. In other experiments nerves that had been stored in sealed capsules at $-15^{\circ} \mathrm{C}$ were brought to room temperature, weighed, and homogenized by hand in $2 \mathrm{ml}$ water containing the internal standard, using a silylized Potter-Elverhjem glass homogenizer. Protein was coagulated as above.

Clear supernatant obtained by centrifugation of the extract (or homogenate) after precipitation of protein was passed through a small column $(0.5 \mathrm{~cm} \times$ $6 \mathrm{~cm}$ ) of basic ion-exchange resin (Bio-Rad AG2 $\times 8$ ) freshly regenerated with $3 \mathrm{ml} 1.0-\mathrm{M} \mathrm{KOH}$ and washed with $30-40 \mathrm{ml} \mathrm{CO} \mathrm{CO}_{2}$ free distilled water. Eluate, washed through with 3 bed volumes of water, was collected in a B14 tube and evaporated to dryness under reduced pressure with a rotary evaporator and a water bath at $60^{\circ} \mathrm{C}$. Residual solid was taken up in $0.25 \mathrm{ml}$ water, the solution transferred to a pointed (C14) centrifuge tube, and solvent removed using a hot-block at $60^{\circ} \mathrm{C}$ and nitrogen $(1 \mathrm{l} / \mathrm{min})$ streamed through a Pasteur pipette over the liquid surface.

The dry residue was silylated by adding $20 \mu \mathrm{l}$ BSA (bis-trimethylsilylacetamide) and $10 \mu \mathrm{l}$ TMCS (trimethylchlorosilane), flushing with dry $\mathrm{N}_{2}$, and closing with a stopper. Reaction was complete after 15 minutes in a hot-block at $60^{\circ} \mathrm{C}$. When cool the mixture was diluted with $45 \mu \mathrm{l} 60-80^{\circ}$ petroleum ether (dried over $\mathrm{Na}_{2} \mathrm{SO}_{4}$ ), giving a mobile liquid convenient for analysis by gas chromatography. For this purpose a Perkin-Elmer F11 apparatus fitted with a 
capillary column $(50 \mathrm{~m} \times 0.020 \mathrm{~m})$ of stainless steel coated with silicone gum (E301) was used with argon $(55 \mathrm{kPa})$ as carrier; a flame ionization detector was employed in conjunction with an amplifier usually set for attenuation at $\times 50$ or $\times 20$. Each specimen was chromatographed isothermally at $195^{\circ} \mathrm{C}$ and again with temperature-programming (see Fig. 2). Isothermal operation was used for identification of peaks and (for major peaks) for quantification, which was more accurately achieved from the programmed runs.

Identification of peaks was by comparison with the retentions, relative to that for arabitol, of the derivatives of standard substances. Quantification was through peak areas, measured from chords (a) at 0.75 and (b) at 0.375 of the peak height. The relationship for Gaussian distributions - that is, peak area $=0.9726 \times\left[c(b-a / 2)^{2}\right] /[b-a]$, was employed where $\mathrm{c}=0.75 \times$ peak height, taking the constant as unity and common to all peaks. The arabitol peak was taken as standard and a specific factor applied for each peak to reduce it to a standard area per $\mu \mathrm{mol}$ taken originally for extraction. These constants

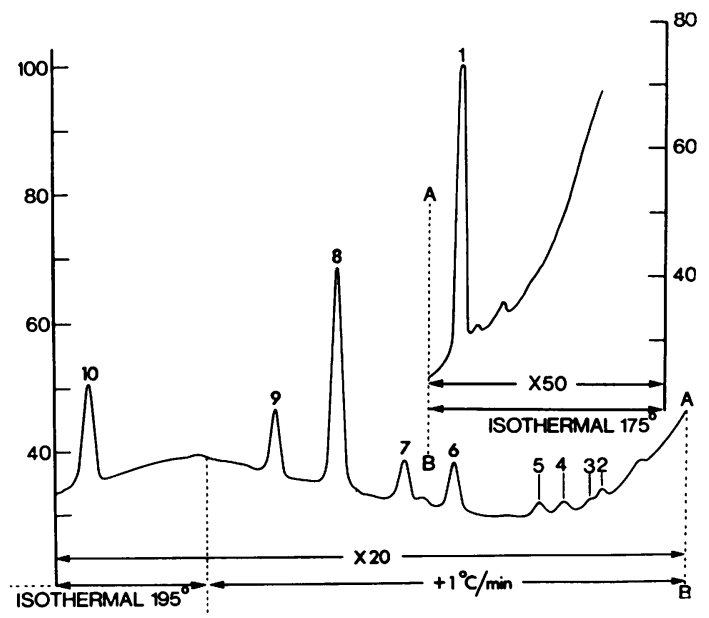

FIG. 2 Gas chromatogram of trimethylsilyl derivations of polyhydric substances extracted from dried sciatic nerve of rat maintained for seven weeks on galactose diet. Open tube capillary column with silicone gum E301 with attenuations and temperature programme as marked and with uniform chart-speed; interval between peaks (1)-(8) is 23.5 min. Peaks are (1) arabitol added as standard to extract; (2) fructose; (3) galactose-1; (4) glucose-1; (5) galactose-2; (6) glucose-2; (7) galactose-3; (8) galactitol; (9) glucose-3; (10) inositol.
(Ward et al., 1972) were redetermined for the conditions in the present work by treating known volumes of standard solutions of dried fructose, glucose, galactose, galactitol, and inositol exactly as for the nerves. The lower limit for measurement was about $0.02 \mu \mathrm{mol} / \mathrm{g}$ fresh tissue for each substance. Concentrations of polyols were calculated from the gas chromatograms as $\mu \mathrm{mol} / \mathrm{g}$ fresh tissue using weights estimated as above.

MORPHOLOGICAL TECHNIQUES For the examination of fascicular area a segment of the sciatic nerve was removed at a standard site immediately distal to the sciatic notch under ether anaesthesia. Frozen sections $15-20 \mu \mathrm{m}$ in thickness were cut on a cryostat, stained with $1 \%$ aqueous light green and photographed at a final magnification of $\times 160$. Fascicular area was estimated by tracing the outline of the inner border of the perineurium on to graph paper and measuring the enclosed area.

Quantitative histometric and ultrastructural observations were undertaken on the tibial nerve, as the electrophysiological observations were made on this nerve. After anaesthetizing the animal with ether arterial perfusion was performed by introducing a catheter into the descending thoracic aorta and incising the right atrium for drainage. Perfusion was undertaken with cacodylate-buffered paraformaldehyde-glutaraldehyde fixative at $4^{\circ} \mathrm{C}$ (Cotran and Karnovsky, 1968), preceded by a brief perfusion with the same solution at $37^{\circ} \mathrm{C}$. The left tibial nerve between the knee and ankle was freed from connective tissues and removed in one piece without stretching. The nerve segments were then immersed for three hours in the fixative, washed in buffer containing $10 \%$ sucrose, and postfixed in a $1 \%$ cacodylatebuffered solution of osmium tetroxide for three hours. After dehydration in graded concentrations of ethanol the nerves were embedded in Araldite.

For the examination of isolated nerve fibres portions from the lower part of the tibial nerve up to $1.5 \mathrm{~cm}$ in length were fixed and dehydrated as already described, but postfixation was continued for five hours. Single fibre preparations were obtained by teasing in unpolymerized Araldite. Measurements of myelinated fibre numbers and diameter were made on photographs of semithin sections of Aralditeembedded material, $1-1.5 \mu \mathrm{m}$ in thickness and stained with thionin and acridine orange, at a final magnification of $\times 1000$. These were obtained from a constant site in the tibial nerve in the upper part of the lower leg. The external diameter of the fibres was measured in $1-\mu \mathrm{m}$ steps with a magnifying eyepiece and a graticule scale. The narrower dimension was measured for fibres with an elliptical outline. All the myelinated fibres were measured for two control and two 
experimental nerves, and the diameter of the 20 largest fibres was recorded for all the animals. In the animals in which measurements were not made on all the fibres, average fibre diameter was estimated employing a sampling technique. The diameter of those fibres that were intersected by 16 equidistant radiating lines drawn from the centre of the fascicle was measured. Average fibre diameter was calculated by multiplying the number of fibres in each $1-\mu \mathrm{m}$ diameter group by the median diameter value of the group, adding together the values for all the groups, and dividing the sum by the total number of fibres.

The ultrastructure of myelinated and unmyelinated fibres was studied in transverse and longitudinal ultra-thin sections cut on a Porter-Blum MT2 ultramicrotome, stained with $12.5 \%$ methanolic uranyl acetate and lead citrate, and examined with a Siemens Elmiskop 101.

Finally, the relationship between myelin thickness and axon circumference was investigated by counting the number of myelin lamellae on electron micrographs at a final magnification of $\times 20000$ using a magnifying eyepiece. Axon circumference was measured with a map meter. Observations were made over the whole range of fibre size in a single transverse section of the tibial nerve. Fibres sectioned obliquely, in the paranodal region or at Schmidt-Lanterman incisures, were not included.

\section{RESULTS}

The galactose-fed animals remained healthy but did not gain weight as rapidly as the control animals and developed cataracts after about two months. There was no evidence of muscle weakness or clinical evidence of neuropathy. Blood glucose concentrations in control and galactosefed animals varied between 5.5-7.0 and 5.5-9.3 $\mathrm{mmol} / \mathrm{l}(100-125$ and $100-165 \mathrm{mg} / 100 \mathrm{ml})$ respectively.

ELECTROPHYSIOLOGICAL OBSERVATIONS The results of serial motor nerve conduction velocity estimations in galactose-fed and control animals are shown in Fig. 3. Conduction velocity was consistently reduced in the experimental animals and remained so throughout the period of the investigation. No tendency either towards recovery or progressive deterioration was evident. The mean $( \pm \mathrm{SD})$ value for the galactose-fed rats was $37.2 \pm 3.3 \mathrm{~m} / \mathrm{s}$ and that for the control group $49.2 \pm 5.5 \mathrm{~m} / \mathrm{s}$. This difference is significant $(\mathrm{P}<0.001)$.

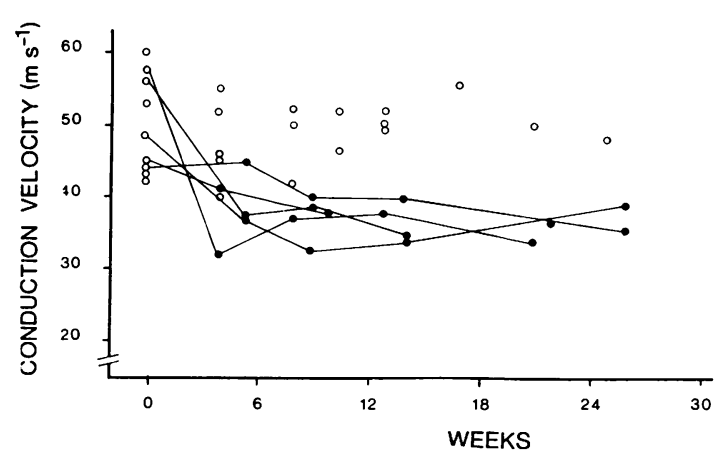

FIG. 3 Serial measurements of motor conduction velocity in tibial nerve for galactose fed animals (०) plotted against survival time in weeks. Results for control animals indicated by open circles.

\section{BIOCHEMICAL OBSERVATIONS}

Water content of nerve The percentage difference between the wet and dry weights of segments of the sciatic nerve was obtained for five galactosefed and five control animals. The mean values were $61.0 \pm 2.6$ and $70.4 \pm 5.9$ respectively. This difference is significant $(\mathrm{P} \approx 0.01)$.

Polyhydric substances There was a clear qualitative distinction between test and control nerves in that the predominant peak in eight test nerves was that ascribable to galactitol (Fig. 2), whereas no such peak was seen in any of five controls. Quantification was undertaken with seven of the experimental and three control nerves and demonstrated a further difference in that the myoinositol content of the test nerves was about half that of the controls. Galactose was present in appreciable quantities in the experimental specimens but detected in only one of the five controls. The explanation of this anomalous finding is uncertain and the possibility of contamination of the sample cannot be excluded. The quantitative results are summarized in Table 1, where means and standard deviations are given in $\mu \mathrm{mol} / \mathrm{g}$ fresh tissue.

Values for all five substances were independent of the time of maintenance on the galactose diet. Sums of peaks for each sugar were taken for quantification, with the untested assumption that the area factors were independent of the distribution of the possible forms. Small amounts of 
TABLE 1

POLYHYDRIC SUBSTANCES ( $\mu \mathrm{mol} / \mathrm{g}$ FRESH TISSUE) IN RAT SCIATIC NERVES (RELATIVE RETENTIONS AND PEAK-AREA MOLAR FACTORS ALSO SHOWN)

\begin{tabular}{|c|c|c|c|c|c|c|}
\hline & Glucose & Fructose & Galactose & Galactitol & Inositol & Total \\
\hline \multicolumn{7}{|l|}{ Galactose-fed (7) } \\
\hline Mean & 4.75 & 0.53 & 2.96 & 10.07 & 1.71 & 20.02 \\
\hline & 3.41 & 0.64 & 4.80 & 4.06 & 0.56 & \\
\hline \multicolumn{7}{|l|}{ Control (3) } \\
\hline Mean & 6.33 & 0.37 & $(<0.40)$ & $<0.02$ & 3.65 & 10.77 \\
\hline & 5.24 & 0.53 & - & - & 0.65 & - \\
\hline \multicolumn{6}{|l|}{ Significance of difference } & - \\
\hline Relative retention on & 1.57 & 1.33 & 1.42 & 2.48 & 4.27 & \\
\hline $\mathrm{E} 301 / 195^{\circ} \mathrm{C}$ for & 1.91 & $\frac{.36}{1.36}$ & 1.70 & & & \\
\hline arabitol $=1.00$ & $\overline{2.73}$ & 1.44 & $\overline{2.01}$ & & & \\
\hline Peak-area molar factor & & 143 & 133 & 073 & 066 & \\
\hline
\end{tabular}

sorbitol (about $0.2 \mu \mathrm{mol} / \mathrm{g}$ ) were detected in most samples. The sorbitol peak (retention 2.41) was poorly resolved from that of galactitol.

\section{MORPHOMETRIC OBSERVATIONS}

Fascicular area Sciatic nerve fascicular area for eight galactose-fed animals was $1.92 \pm 0.17 \mathrm{~mm}^{2}$; for five control nerves the corresponding value was $1.50 \pm 0.21 \mathrm{~mm}^{2}$. This difference is significant $(\mathrm{P}<0.01)$.

Myelinated nerve fibre population The values for the total number of fibres and their size distribution in the tibial nerve for the two experimental and two control nerves in which all the fibres were measured are shown in Table 2 . The values are closely similar in the two groups. The size distributions are presented in the form of histograms (Fig. 4). No systematic differences areo evident.

Maximum fibre diameter was measured in eight experimental and eight control nerves The mean value for the former was $10.7 \pm 0.44 \mu \mathrm{m}$ and for the latter was $9.8 \pm 0.78 \mu \mathrm{m}$. This differ= ence is significant $(0.05>\mathrm{P}>0.01)$. The corres ponding values for average fibre diameter were $5.8 \pm 0.51$ and $5.2 \pm 0.37 \mu \mathrm{m}$. This difference is also significant $(\mathrm{P}<0.01)$.

Teased fibre preparations were examined from the tibial nerves of four galactose-fed and three control animals. Evidence of paranodal or segmental demyelination was not detected. The relationship between internodal length and fibre

TABLE 2

NUMBERS OF FIBRES IN $1 \mu \mathrm{m}$ DIAMETER GROUPS FOR MYELINATED FIBRES IN TIBIAL NERVE OF CONTROL AND GALACTOSE-FED ANIMALS

\begin{tabular}{|c|c|c|c|c|c|c|c|c|c|c|c|c|c|c|}
\hline \multirow{2}{*}{$\begin{array}{l}\text { Survival } \\
\text { time } \\
\text { (weeks) }\end{array}$} & \multicolumn{13}{|c|}{ Fibre diameter $(\mu \mathrm{m})$} & \multirow{2}{*}{$\begin{array}{l}\text { Total } \\
\text { fibre } \\
\text { number }\end{array}$} \\
\hline & $1-2$ & 3 & 4 & 5 & 6 & 7 & 8 & 9 & 10 & 11 & 12 & 13 & 14 & \\
\hline $\begin{array}{c}\text { Control } \\
21 \\
25\end{array}$ & $\begin{array}{l}121 \\
215\end{array}$ & $\begin{array}{l}355 \\
437\end{array}$ & $\begin{array}{l}351 \\
378\end{array}$ & $\begin{array}{l}410 \\
491\end{array}$ & $\begin{array}{l}618 \\
771\end{array}$ & $\begin{array}{l}635 \\
635\end{array}$ & $\begin{array}{l}347 \\
427\end{array}$ & $\begin{array}{l}109 \\
141\end{array}$ & $\begin{array}{l}48 \\
50\end{array}$ & $\begin{array}{l}18 \\
11\end{array}$ & $\begin{array}{l}4 \\
6\end{array}$ & $\begin{array}{l}3 \\
3\end{array}$ & 2 & $\begin{array}{l}3019 \\
3567\end{array}$ \\
\hline $\begin{array}{c}\text { Galactose } \\
21 \\
25\end{array}$ & $\begin{array}{l}200 \\
180\end{array}$ & $\begin{array}{l}370 \\
391\end{array}$ & $\begin{array}{l}293 \\
489\end{array}$ & $\begin{array}{l}365 \\
572\end{array}$ & $\begin{array}{l}508 \\
570\end{array}$ & $\begin{array}{l}596 \\
445\end{array}$ & $\begin{array}{l}420 \\
226\end{array}$ & $\begin{array}{r}219 \\
86\end{array}$ & $\begin{array}{l}74 \\
40\end{array}$ & $\begin{array}{r}27 \\
6\end{array}$ & $\begin{array}{l}8 \\
2\end{array}$ & 2 & 2 & $\begin{array}{l}3084 \\
3007\end{array}$ \\
\hline
\end{tabular}




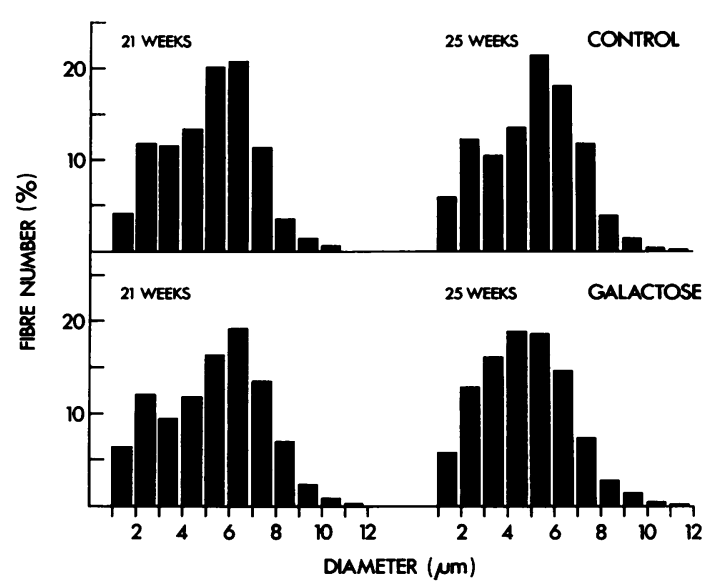

FIG. 4 Size-frequency distributions for myelinated fibres in tibial nerve from control and galactose-fed animals with survival times of 21 and 25 weeks.

diameter was assessed. This was approximately linear. Regression lines were calculated and the coefficients are given in Table 3 . No statistically significant difference is present between the slopes for the control and experimental nerves $(P>0.05)$.

The degree of myelination was compared over the whole range of fibre size for the tibial nerve for one galactose-fed and one control animal.
TABLE 3

RELATIONSHIP BETWEEN INTERNODAL LENGTH AND FIBRE DIAMETER: REGRESSION COEFFICIENTS

\begin{tabular}{ccc}
\hline \multirow{2}{*}{$\begin{array}{c}\text { Survival times } \\
\text { (weeks) }\end{array}$} & Control & Slope coefficients \\
\cline { 2 - 3 } & $0.071 \pm 0.00752$ & $0.075 \pm 0.00521$ \\
16 & $0.078 \pm 0.00516$ & $0.074 \pm 0.00572$ \\
21 & $0.065 \pm 0.00405$ & $0.063 \pm 0.00509$ \\
25 & & $0.078 \pm 0.00532$ \\
26 & & \\
\hline
\end{tabular}

The relationship between the number of myelin lamellae and axon circumference was approximately linear in both (Figs. 5 and 6). Linear regression lines were calculated and did not differ significantly.

NERVE ULTRASTRUCTURE Examination of the ultrastructural features of control and experimental nerves revealed no detectable differences. The myelinated and unmyelinated fibres appeared entirely normal in the galactose-fed animals. In particular, no axonal or nodal changes were seen and nothing was observed to suggest abnormal hydration of the Schwann cells. The endoneurial blood vessels appeared unaltered and no abnormal material was observed in the endoneurium.

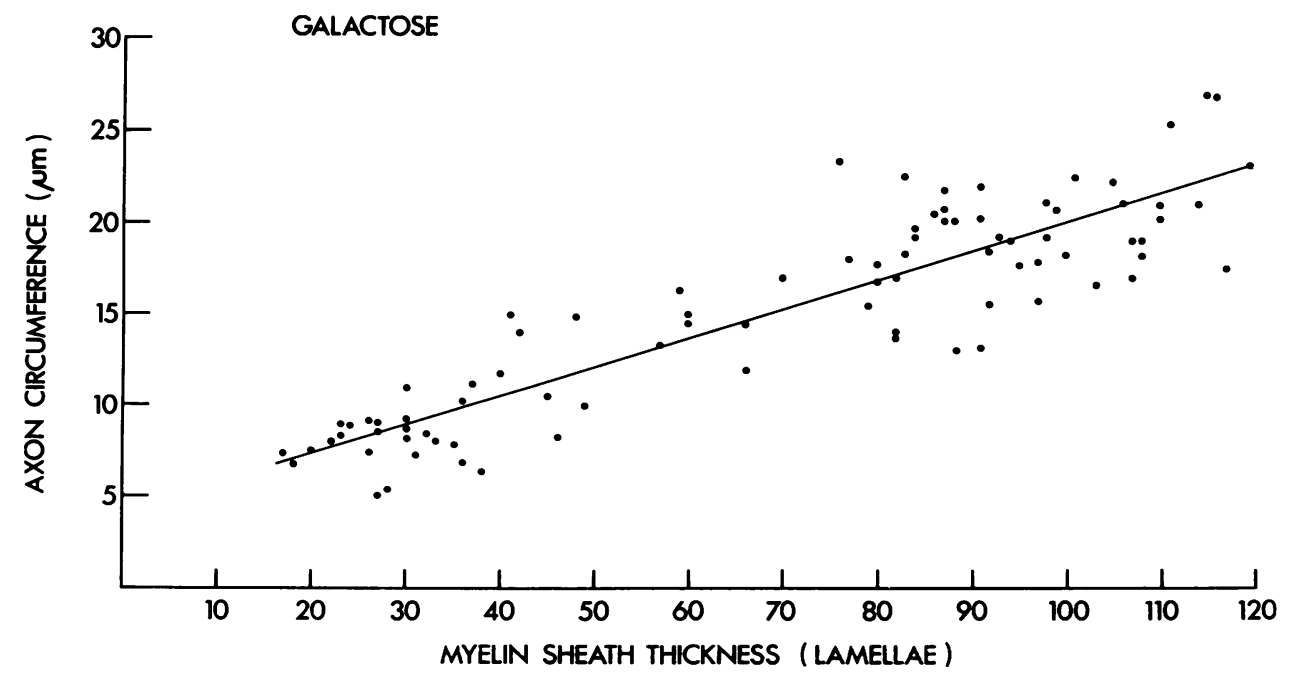

FIG. 5 Relationship between axon circumference and number of myelin lamellae in tibial nerve for galactose-fed animal with survival time of 25 weeks. 


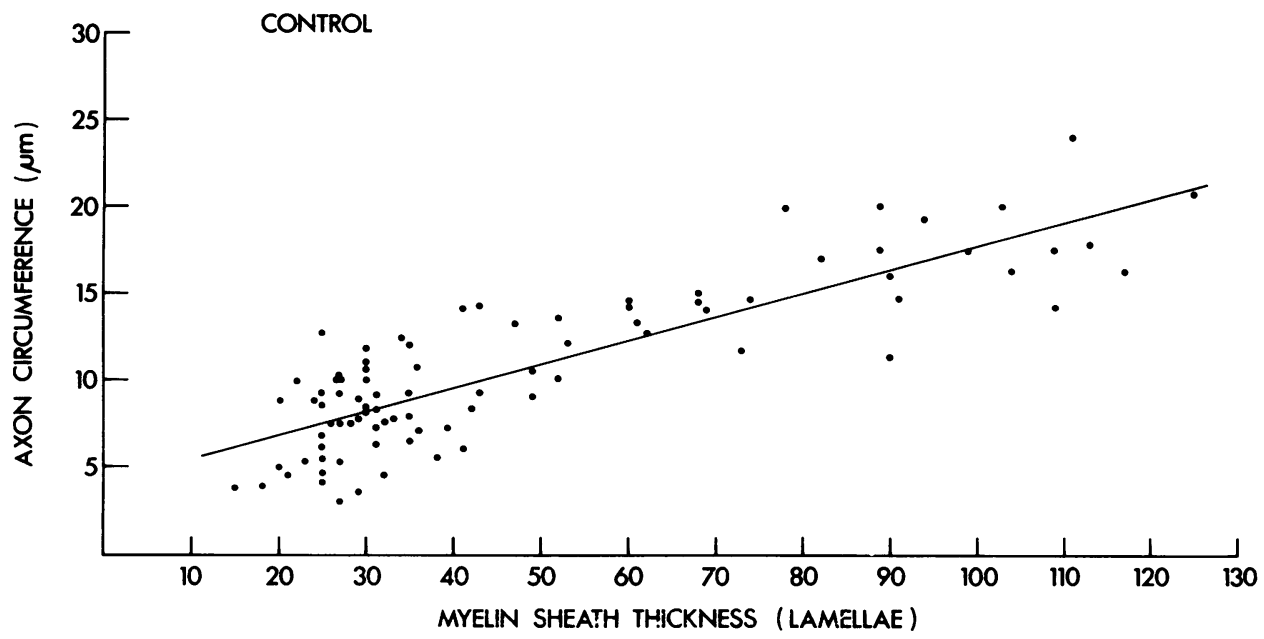

FIG. 6 Relationship between axon circumference and number of myelin lamellae in tibial nerve for control animal with survival time of 25 weeks.

\section{DISCUSSION}

The present observations have confirmed that galactose feeding to rats gives rise to reduced motor nerve conduction velocity, as was originally reported by Gabbay and Snider (1972). Although maximum fibre diameter is slightly reduced in the galactose-fed animals as compared with the controls, the degree of reduction, which is less than $1 \mu \mathrm{m}$, is clearly insufficient to explain the diminution in conduction velocity. The degree of reduction is similar to that in experimental diabetes, where Sharma and Thomas (1974) failed to detect any reduction in fibre diameter. Re-examination of these results, however, also indicates that there is a slight but statistically significant reduction in diameter in the diabetic animals as compared with age-matched controls. The average diameter of myelinated fibres in the sural nerve in streptozotocin-induced diabetic animals with a survival time of up to 28 weeks was $0.4 \mu \mathrm{m}$ less than the controls, which is again insufficient to explain the reduction in conduction velocity. It is unlikely that fibre diameter diminishes; inspection of the results suggests that the difference is explained by a retardation in growth in the diabetic animals as compared with the controls. The same is probably true of the present observations. During the past two decades, during which the explanation of reductions in conduction velocity both in human neuropathies and in experimental models has been extensively explored, the investigations have concentrated in correlating the electrophysiological changes with alterations in the geometry of nerve fibres. In both experimental diabetes and after galactose feeding we have situations in which alterations of a biochemical nature are probably responsible.

Our biochemical studies have also confirmed Gabbay and Snider's observation that galactitol accumulates in peripheral nerve in substantial quantities. The site of accumulation of the galactitol is uncertain. Aldose reductase is known to be localized within Schwann cells (Gabbay and O'Sullivan, 1968) and would be capable of converting galactose to galactitol. Galactitol, like other sugar alcohols, traverses cell membranes slowly (Le Fevre and Davies, 1951). Sorbitol dehydrogenase, which converts sorbitol to fructose, is able to metabolize only sorbitol. The galactitol would therefore be expected to accumulate within Schwann cells and possibly this might result in osmotic overhydration of these cells (Gabbay, 1973). However, there were no ultrastructural changes in our galactose-fed animals to suggest that this occurs. Possibly the galactitol slowly leaks into the endoneurium, where it accumulates. Further studies are necessary to 
determine the precise localization of the galactitol. Although the macroscopic swelling of peripheral nerves found by Gabbay and Snider was not seen in our material, the fascicular area of the sciatic nerve was slightly but significantly increased, as was the water content. Since the number and diameter of the myelinated fibres is not increased, the increase in fascicular area is likely to be the result of an expansion of the endoneurial connective tissue compartment. The extent of the endoneurial connective tissue spaces has not been assessed quantitatively. This would be difficult to achieve as it would demand observations on sections that had not been subjected to fixation or dehydration. No abnormal material was observed in the endoneurial spaces in the galactose-fed animals either on light or electron microscopy.

The explanation of the reduction in conduction velocity both in experimental diabetes and in galactose-fed animals has yet to be established. Eliasson (1969) found that in alloxan-diabetic animals the electrical properties of the nodes of Ranvier were unaltered within the limits of the technique employed. Internodal capacitance was normal whereas internodal resistance was reduced. It was suggested that 'leakiness' of the myelin might be responsible for the reduced conduction velocity, possibly caused by oedema of the myelin sheath or an alteration in its composition. No indication of abnormal periodicity of the myelin to suggest the presence of oedema was detected by Sharma and Thomas (1974). Eliasson's results did not exclude an abnormality in the generation of the nodal action potential as contributing to the reduced conduction velocity. If the rise time of the nodal action potential were diminished it would lead to a delay in the activation of the following node and therefore to a reduced conduction velocity. We are at present investigating this possibility.

The myoinositol content of peripheral nerve is known to be reduced both in experimental diabetes (Stewart et al., 1967; Greene et al., 1975) and after galactose feeding (Stewart et al., 1967; Gabbay and Snider, 1972; and present results). In a recent important study Greene et al. (1975) found that the addition of myoinositol to the diet prevented the reduction in conduction velocity in experimental diabetes in rats. It is not yet known whether this also applies to the galactosefed animals.

Probably polyphosphoinositides are localized in plasma membranes, including those of neurones (Eichberg and Hauser, 1973). Both di- and triphosphoinositides are present, the former predominating. Enzymes that catalyze phosphoinositides are associated with the cell surface. It has been postulated that such polyphosphoinositides may be involved in the generation and propagation of action potentials. Both di- and triphosphoinositides show a rapid turnover rate in nerve trunks (Yagihara et al., 1969; White and Larrabee, 1973). The hypotheses advanced have utilized the $\mathrm{Ca}^{2+}$ ion-binding affinity exhibited by di- and triphosphoinositides, and have suggested that by interconversions between different inositol lipids the quantity of $\mathrm{Ca}^{2+}$ ions bound at specific sites in the plasma membrane could be varied. This might open or close $\mathrm{Na}^{+}$or $\mathrm{K}^{+}$channels and thus be involved in the generation and propagation of action potentials. Kai and Hawthorne (1969) and Hawthorne and Kai (1970) originally suggested that $\mathrm{Ca}^{2+}$ ions bound to pairs of di- or triphosphoinositide molecules might obstruct an ion channel through the plasma membrane. Dephosphorylation to phosphatidylinositol, which has a lower affinity for $\mathrm{Ca}^{2+}$ ions, might release the $\mathrm{Ca}^{2+}$ and open the channel. A somewhat different suggestion was made by Hendrickson and Reinertsen (1969), who concluded that triphosphoinositide possessed a higher affinity for $\mathrm{Ca}^{2+}$ than diphosphoinositide and postulated (Hendrickson and Reinertsen, 1971) that interconversion between these two polyphosphoinositides might be sufficient to control the opening and closure of $\mathrm{Na}^{+}$channels through the axon membrane. There are certain difficulties at present in accepting either of these hypotheses (see Michell, 1975), but the possible role of reduced nerve myoinositol in relation to reduced nerve conduction velocity clearly requires further exploration.

The mechanism for the reduction in nerve myoinositol, both in diabetes and after galactose feeding, is obscure. Possibly galactitol and sorbitol act as competitive inhibitors in the local formation of polyphosphoinositides. A further observation that also requires explanation is that experimental hypermyoinositolaemia in rats is 
associated with reduced nerve conduction velocity (De Jesus et al., 1974). Moreover, it is entirely uncertain whether the mechanisms that give rise to reduced conduction in these various experimental situations have any relevance to the structural neuropathies that may appear in human diabetes mellitus or in chronic renal failure (see Sharma and Thomas, 1974).

We are indebted to the British Diabetic Association for financial support and to Professor J. N. Hawthorne for helpful discussion.

\section{REFERENCES}

Cotran, R. S., and Karnovsky, M. J. (1968). Ultrastructural studies on the permeability of the mesothelium to horseradish peroxidase. Journal of Cell Biology, 37, 123-137.

De Jesus, Jr, P. V., Clements, Jr, R. S., and Winegard, A. I. (1974). Hypermyoinositolemic polyneuropathy in rats. A possible mechanism for uremic polyneuropathy. Journal of the Neurological Sciences, 21, 237-249.

Eichberg, J., and Hauser, G. (1973). The subcellular distribution of polyphosphoinositides in myelinated and unmyelinated rat brain. Biochimica et Biophysica Acta, 326, 210-223.

Eliasson, S. G. (1969). Properties of isolated nerve fibres from alloxanized rats. Journal of Neurology, Neurosurgery, and Psychiatry, 32, 525-529.

Gabbay, K. H. (1973). The sorbitol pathway and the complications of diabetes. New England Journal of Medicine, 288, 831-836.

Gabbay, K. H., and O'Sullivan, J. B. (1968). The sorbitol pathway: enzyme localization and content in normal and diabetic nerve and cord. Diabetes, 17, 239-243.

Gabbay, K. H., and Snider, J. J. (1972). Nerve conduction defect in galactose-fed rats. Diabetes, 21, 295-300.

Gitzelmann, R., Curtius, H. C., and Schneller, I. (1967). Galactitol and galactose-1-phosphate in the lens of a galactosemic infant. Experimental Eye Research, 6, 1-3.

Greene, D. A., De Jesus, Jr, P. V., and Winegrad, A. I. (1975). Effects of insulin and dietary myoinositol on impaired peripheral motor nerve conduction velocity in acute streptozotocin diabetes. Journal of Clinical Investigation, 55, 1326-1336.

Hawthorne, J. N., and Kai, M. (1970). Metabolism of phosphoinositides. In Handbook of Neurochemistry, pp. 491-508. Edited by A. Lajtha. Plenum Press: New York.
Hendrickson, H. S., and Reinertsen, J. L. (1969). Comparison of metal-binding properties of trans-1,2-cyclohexanediol diphosphate and deacylated phosphoinositides. Biochemistry, 8, 4855-4858.

Hendrickson, H.S., and Reinertsen, J. L. (1971). Phosphoinositide interconversion: a model for control of $\mathrm{Na}^{+}$ and $\mathrm{K}^{+}$permeability in the nerve axon membrane. Biochemical and Biophysical Research Communications, 44, 1258-1264.

Kai, M., and Hawthorne, J. N. (1969). Physiological significance of polyphosphoinositides in brain. Annals of the New York Academy of Sciences, 165, 761-773.

Kinoshita, J. H. (1965). Cataracts in galactosemia. Investigative Ophthalmology, 4, 786-799.

Kinoshita, J. H., Merola, L. O., Satoh, K., and Dikmak, E. (1962). Osmotic changes caused by the accumulation of dulcitol in the lenses of rats fed with galactose. Nature, 194, 1085-1087.

Le Fevre, P. G., and Davies, R. I. (1951). Active transport into the human erythrocyte: evidence from comparative kinetics and competition among monosaccharides. Journal of General Physiology, 34, 515-524.

Michell, R. H. (1975). Inositol phospholipids and cell surface receptor function. Biochimicaet Biophysica Acta, 415, 81-147.

Sharma, A. K., and Thomas, P. K. (1974). Peripheral nerve structure and function in experimental diabetes. Journal of the Neurological Sciences, 23, 1-15.

Stewart, M. A., Sherman, W. R., Kurien, M. M., Moonsammy, G. I., and Wisgerhof, M. (1967). Polyol accumulation in nervous tissue of rats with experimental diabetes and galactosaemia. Journal of Neurochemistry, 14, 1057-1066.

Van Heyningen, R. (1959). Formation of polyols by the lens of the rat with 'sugar' cataract. Nature, 184, 194-195.

Ward, J. D., Baker, R. W. R., and Davies, B. H. (1972). Effect of blood sugar control on the accumulation of sorbitol and fructose in nervous tissues. Diabetes, 21, 1173-1178.

White, G. L., and Larrabee, M. G. (1973). Phosphoinositides and other phospholipids in sympathetic ganglia and nerve trunks of rats. Effects of neuronal activity and inositol analogs [ $\sigma-$ and $\gamma$-hexachlorocyclohexane (lindane)] on (32P)-labelling, synaptic transmission and axonal conduction. Journal of Neurochemistry, 20, 783-798.

Yagihara, Y., Salway, J. G., and Hawthorne, J. N. (1969). Incorporation of $32 \mathrm{P}$ in vitro into triphosphoinositide and related lipids of rat superior cervical ganglia and vagus nerves. Journal of Neurochemistry, 16, 1133-1139. 